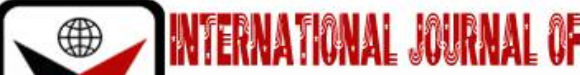

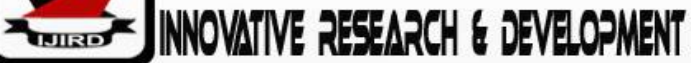

ISSN 2278 - 0211 (Online)

\section{Factors Influencing Farmer's Willingness to Adopt Pearl Millet Production in Tigania West District, Kenya}

Victor M Akwalu
Lecturer, Business Management, Meru University of Science and Technology, Kenya
Samuel N.Mbogori
Lecturer, Business Management, Meru University of Science and Technology, Kenya
Gideon. A. Obare
Professor, Agricultural Economics and Business Management, Egerton University, Kenya
Bernard. K. Njehia
Professor, Agribusiness Management and Trade, Kenyatta University, Kenya

\begin{abstract}
:
Pearl millet crop has the potential to mitigate food unavailability and variability risks in Tigania West district due to its sturdiness and suitability to low and marginal areas. This study aimed at identifying and analyzing the factors influencing farmer's willingness to adopt pearl millet production in Tigania West District. A sample of 160 farmers was selected from the population of the small-scale farmers in the district. Primary data were collected through administration of a structured questionnaire. Secondary data was sourced through extensive literature review. A binomial logit model was applied to establish the farmers' willingness to grow pearl millet. Computer statistical programs, STATA and SPSS were used in the process of data management and analysis. The study revealed that household head's age, education level, land size and household size are statistically significant factors in influencing a farmer's willingness to grow pearl millet crop. The study showed that older farmers are more willing to adopt pearl millet cultivation than young farmers and the more the education level the more the willingness to grow pearl millet by the farmers. These older farmers can be sought as the target units by the policy makers
\end{abstract}

Keywords: Adoption, binomial logit model, utility

\section{Introduction}

Pearl millet is the most widely grown type of millet, accounting for about 50 percent of total world production. Today, pearl millet is grown on over 26 million hectares worldwide. African farmers produce about 40 percent of the world's millet, but India is the largest producer of the crop, both in terms of area (about 9.1 million hectares) and production (about 7.3 million tons) (Robert, 2002).

According to Leisinger et al., 1995, the food value of pearl millet is very high. Trials in India have shown that pearl millet is nutritionally superior for human growth when compared to maize and rice. The protein content of pearl millet is higher than maize and has a relatively high vitamin A content. In addition to tolerating hot and dry climates, pearl millet is able to produce reasonable yields on marginal soils, where other crops would fail. Low fertility and high salinity are frequent problems in millet producing areas. At the same time, pearl millet responds very favorably to slight improvements in growing conditions such as irrigation and tillage.

Pearl millet's deep Root Penetration offers the crop the ability to survive under very harsh conditions. Pearl millet roots can penetrate up to $180 \mathrm{~cm}$ deep, with approximately two-thirds of the root system in the top $45 \%$ of the soil zone (Mangat, et al., 1999). This deep root penetration may help millet species to exploit soil water more effectively and therefore overcome drought.

Pearl millet's advantage over other cereals is that it can and is grown in marginal agricultural areas where annual rainfall is variable, unpredictable and very low $(200-500 \mathrm{~mm})$ and where daily temperatures reach in excess of $30^{\circ} \mathrm{C}$ (ICRISAT and FAO, 1996). Moreover, its nutrient content and properties are equivalent or even superior to those of other cereals (Obilana and Manyasa, 2002).

\section{Materials and Methods}

\subsection{Study Area}

The study was done in Tigania west district between the months of July and September 2010. Tigania west district was selected because there has been absolute pearl millet abandonment in the district. Initially pearl millet used to be the major crop grown and during those periods incidences of food insecurity were rare. Tigania West District is situated on 
the western side of former Meru North district down the slopes of Nyambene ranges. The district covers an area of 386 sq $\mathrm{km}$ with a population of 125,000 . It comprises of four administrative divisions, namely Akithi, Tigania West, Mituntu and Uringu. The district is relatively agriculturally potential, with the major economic activity being agriculture and livestock rearing. The rainfall received in the division is bimodal in nature being received in March/May and October/December. The division receives precipitation ranging from $800-1000 \mathrm{~mm}$ per annum. Long rains are experienced in OctoberDecember while short rains in March to May. The district is generally classified as semi-arid.

\subsection{Data and Sampling Design}

A sample of 160 farmers was selected from the population of the small-scale farmers in the district. Primary data were obtained through administration of a structured questionnaire to the respondents. Multistage sampling methodology was applied. Tigania west district was purposively selected due to its absolute pearl millet abandonment characteristics. Three divisions (Akithi, Mituntu and Uringu) were then randomly selected and from each division, two locations were randomly selected. Through proportionate sampling, 160 small scale farmers were randomly selected from the six locations.

\subsection{Analysis}

This study was informed by the theory of utility maximization as developed and used by Caviglia-Harris, (2003). The underlying utility function, which ranks the preference of the $i^{\text {th }}$ individual depends on a vector of personal attributes (for example age, education, income and occupation) and farm characteristics and a vector of management characteristics (for example perceptions and attitude towards risk) associated with specific initiatives. According to Caviglia-Harris, (2003), the decision to adopt a new crop or not depends on whether the new crop gives the farmer superior utility than the existing crop. It is assumed that farmers are after achieving utility maximization derived from a given new crop or new technology and therefore farmers carry out a comparison of the expected net returns of the new crop / technology with and without it. Putting across three assumptions that; (1) the farmer is endowed with $R$ amount of resources, (2) the farmer currently produces $X_{i}$ crops where $i=(1,2, \ldots \ldots n)$ are crops such as maize, beans and sorghum and (3) that the new crop/ technology (pearl millet) is represented by $P$. The farmer is also assumed to have scarcity of resources $R$ which means that for the farmer to adopt pearl millet production he has to reduce resource allocation meant for the production of the existing $\operatorname{crop}(\mathrm{s})$ so as to allocate these resources to pearl millet production. Under such circumstances farmer will only prefer to adopt pearl millet $P$ and reduce production of maize or any other crop if its expected benefits exceeds benefits from the maize or any other crop, that is $\left(E B_{p}>E B_{1}>E B_{n}\right)$, otherwise the farmer will not adopt pearl millet. Where $P$ - pearl millet, $E B$ - expected benefits, 1 - maize, and $n$ - any other crop(s) grown by the farmer. When the dependent variable happens to be dichotomous, a binary choice model becomes appropriate. Following this, the farmer's decision to adopt pearl millet is denoted by $\tau=1$ and $\tau=0$ for non adoption of pearl millet. However, for binary choice models to be efficient two assumptions have to be satisfied: (i) the farmer is only faced with two alternatives from which he/she can choose one, (ii) an individual's choice depends on his/her characteristics (Ayuk, 1997). Utility maximization framework forms the foundation of the binary choice model. A farmer will only adopt pearl millet if it has the potential of increasing his/her utility. The expected net utility from adopting or not adopting pearl millet given farmer's characteristics can be determined as follows:
$E u_{i} p=f\left(X_{i}\right)+\epsilon_{i}$
$E u_{i} \bar{p}=f\left(w_{i}\right)+\epsilon_{i}$
Eqs ------------1

Where, $E u_{i} p$ is the expected net utility of household i from adopting pearl millet and $E u_{i} \bar{p}$ is the expected net utility of household i from not adopting pearl millet. P denotes pearl millet adopted, $\bar{p}$ denotes pearl millet not adopted while $X_{i}$ and $w_{i}$ are the independent variables denoting farmer's characteristics and $\epsilon_{i}$ is an error term. The expected net utility from each of the decisions is then compared such that: $E u_{i} p-E u_{i} \bar{p}>0$, or $E u_{i} p-E u_{i} \bar{p}<0$, $\tau$ is then used as an indicator of the farmers decision of whether to adopt pearl millet or not. $\tau=1$ if pearl millet is adopted and $\tau=0$ when not adopted;

$\tau=1$ if $E u_{i} p-E u_{i} \bar{p}>0$ and $\tau=0$ if $E u_{i} p-E u_{i} \bar{p}<0$......

The interpretation of equation (2) according to Caviglia-Harris, (2003) is that, the probability that the ith household adopts pearl millet is based on the expected net utility derived from adoption of pearl millet. Therefore, a farmer can only adopt pearl millet if the expected net utility derived from its adoption is higher than the utility for non adoption of the crop.

In this study the model used to analyze the factors which determine small household farmers willingness to undertake pearl millet cultivation, involves a mix of quantitative and qualitative data. The small household farmer either is willing to produce pearl millet or is not. The dependent variable therefore is dichotomous, meaning it can only take two values, 1 (if the event occurs) and zero (if the event does not occur) eliciting a yes or no answer respectively. A dichotomous estimation entails the application of qualitative response models. In this study logit model was put into application. Following Gujarati (1995) the cumulative logistic distribution function for factors determining small household farmers' willingness to undertake production of pearl millet was specified as:

$p(i)=\frac{1}{1+e^{-z(i)}}$

where $p(i)$ is the probability of the willingness to produce pearl millet by the $\mathrm{i}^{\text {th }}$ farmer and $z(i)$ is a function of $\mathrm{m}$ explanatory variables $X_{i}$ and is expressed as:

$Z_{I}=\beta_{0}+\beta_{1} X_{1}+\beta_{2} X_{2}+\beta_{3} X_{3}+\cdots+\beta_{m} X_{m}$

(2) where $B_{0}$, is the intercept and $B_{i}$ are the slope parameters in the model. The slope tells us how the log-odds in favor of willingness to undertake production of pearl millet change as the independent variables change. From the above equation (1), we would have an estimation problem if we used OLS, because $P i$ is non-linear not only in $X$ but also in $B^{\prime} s$. But equation (1) is intrinsically linear. This can be shown by analyzing equation (1) further. If the probability of willingness to undertake production of pearl millet is given as in equation (1) the probability of not undertaking, is $(1-\boldsymbol{P} \boldsymbol{i})$ as shown below 


$$
1-p(i)=\frac{1}{1-e^{z i}}
$$

The two equations can be written as:

$\frac{p i}{1-p i}=\frac{1+e^{z i}}{1+e^{-z i}}=e^{z i}$.

The conditional distribution of the outcome variable follows a binomial distribution with probability given by the conditional mean $\mathrm{Pi}$. We can rewrite the logistic model in terms of logs as:

$\operatorname{Ln}\left(\frac{p i}{1-p i}\right)=\operatorname{Ln}\left(e^{z i}\right)=z i=B_{0}+B_{1} X_{1}+B_{2} X_{2}+B_{3} X_{3}+\cdots \cdots \cdots+B_{m} X_{m}$

The log of the odds ratio is not only linear in $X$ but also linear in the $B_{i}$ variable and as a result we can use OLS. Taking the stochastic term $\mu_{i}$ into account, the logit econometric model used was:

$Z i=B_{0}+B_{1} X_{1}+B_{2} X_{2}+B_{3} X_{3}+\cdots \cdots \cdots+B_{m} X_{m}+\mu_{i}$

This econometric model was used and run against the potential variables, which were assumed to affect the farmer's willingness to undertake production of pearl millet. It was assumed that the significant explanatory variables would not all have the same level of impact on the decision of the farmer to undertake production of pearl millet or not. The strengths of the logit model are embedded in the special features that it has (Gujarati, 2003). Firstly, although the probabilities lie between 0 and 1 the logits are not so bounded. As the probability of $P$, goes from 0 to 1 (i.e. as $\mathrm{Z}$ varies from $-\infty$ to $+\infty$ ), the logit $L$ goes from $-\infty$ to $+\infty$ meaning the probabilities for the logit model are not linear, though $\boldsymbol{L}$ is linear in $\boldsymbol{X}$. Secondly, it is possible from the model that given a variable $\boldsymbol{X}_{\mathbf{i}}$, we can directly estimate the probability of a farmer adopting pearl millet or otherwise once the coefficients or parameters $\boldsymbol{B}_{0}$ and $\boldsymbol{B}_{\boldsymbol{i}}$ or any number of coefficients have been found.

\begin{tabular}{|c|c|c|c|}
\hline Variables & Value & Measurements & Expected impact \\
\hline Plmltprdn & $\begin{array}{c}\text { Dummy, farmer willingness to } \\
\text { undertake production of pearl millet }\end{array}$ & $\begin{array}{c}1 \text { for willing to adopt and } \\
\text { 0 for not willing. }\end{array}$ & $(+)$ \\
\hline Age & Age of the farmer & Number of years & $(+)$ \\
\hline Hhsize & Household size & $\begin{array}{c}\text { Number of household } \\
\text { members }\end{array}$ & $(+)$ \\
\hline Landsze & Size of the land & Number of acres & $(-+)$ \\
\hline Cultchang & Change in cultural practices & Perceptions & $(-)$ \\
\hline Educlev & Household head education level & Number of years in school & $(-+)$ \\
\hline Gnder & Household Head Gender & 1for Male and 0 for female & $(-)$ \\
\hline Dmkt & Market Distance & Number of kilometers & $(+)$ \\
\hline Offaminc & Off farm income & Kenya Shillings & $(+)$ \\
\hline Borrwd & Access to credit & Yes or No & Yes or No \\
\hline Pastpalm & Grown pearl millet in the past & (n) & \\
\hline
\end{tabular}

Table 1: The Definition of Variables and Their Units of Measurements Used in the Logistic Regression

The empirical model used to analyze the farmer's willingness to grow pearl millet was specified as shown below; Plmltgrow $=B_{0}+B_{1} A$ ge $+B_{2}$ Farmexp $+B_{3}$ Hhsize $+B_{4}$ Landsze $+B_{5}$ Cultchang $+B_{6}+$

Educlev $+B_{7}$ Gnder $+B_{8} D m k t+u_{i}$

where $\boldsymbol{\mu}_{\boldsymbol{i}}$ is the error term. The error term represents other unobservable socio-economic factors which also contribute to the farmer's willingness to grow pearl millet.

\section{Results and Discussion}

\subsection{Determinants of Household's Willingness to Adopt Pearl Millet}

Table 2 reports the variable's coefficients, their standard errors, and the associated p-values at 95\% confidence level. The coefficient column gives the values for the logistic regression coefficients. These coefficients indicate the amount of change expected in the long odds when there is a one-unit change in the predictor variable with all of the other variables in the model held constant. A coefficient close to 0 suggests that there is no change due to the predictor variable. The logodd is a function of the logit distribution. We can represent the logit model in terms of the odds of success verses failure, which is given by:

$p i / 1$<smiles>[Y17][Y17]</smiles>

The logistic transformation (which gives rise to the logit model) is the log of this odds ratio. Hence, model estimates from logit are properly referred to as "log-odds" estimates. The likelihood ratio chi-square of 73.24 with a $p<0.01$ tells us that our model as a whole fit significantly better than a model with no predictors. Household head's Age, education level, gender, off farm income and land size are statistically significant at 5 percent significance level. For every one-unit (one year) change in age, the log odds for willingness to grow pearl millet (versus non willingness) increases by 0.417 . This 
indicates that the more the age of the household heads the higher the willingness to grow pearl millet. This result contradicts past studies. For instance, according to Rogers, 1995 the younger the farmer, the more likely he/she is to adopt innovations early in his/her respective life cycle. Older farmers may have a shorter time horizon and be less likely to invest in novel technologies. Bagi (1983) found that younger farmers had a greater likelihood of adopting improved crop varieties.

The human capital of the farmer is also assumed to have a significant bearing on the decision to adopt new technologies. Most adoption studies have attempted to measure human capital through the farmer's age and their education or years of experience growing the crop (Fernandez et al., 1994; Fernandez et al., 2007).

An increase by one year in the level of education (Educlev) of the household head results to 0.618 increase in the log of odds for willingness to grow pearl millet. Therefore, the higher the farmer's level of education the higher the willingness to grow pearl millet. Education of the farmer has been found to have a positive effect on adoption of Genetically Modified oilseed rape in Germany (Breustedt et al., 2008) and on Bt and HT (herbicide-tolerant) corn adoption in the United States (Fernandez et al., 2002; Marra et al., 2001). It is assumed here that more years of education will increase the probability of adoption, as better educated farmers can be expected to be more aware of the positive benefits associated with new crop enterprises. In addition, if the farm operator has formal agricultural education it is assumed that he/she will be more likely to innovate due to the higher associated skill level. The agricultural system in which the farmer primarily specializes is likely to also influence the farmer's agricultural experience and human capital.

Gender (Gender) of the household head has a negative influence on the household's willingness to grow pearl millet. A male headed household decreases the log odds for willingness to grow pearl millet by 3.699. Therefore, female headed household are more likely to adopt pearl millet than the male headed households Off-farm income has a negative influence on a household's willingness to grow pearl millet. A unit increase in the level of off farm income (Offaminc), decreases the log odds for willingness to grow pearl millet by 0.0005 . This shows that the higher the level of off farm income the less the willingness to grow pearl millet.

Household's land size has a positive influence on their willingness to grow pearl millet. A unit (acre) increase in land size (Landsize) increases the log odds for willingness to grow pearl millet by 1.372. Household's total land size also has a positive influence on the household's willingness to grow pearl millet as indicated in table 2. Land size is widely believed to encourage the adoption of new enterprises (Daberkow \& McBride, 2003). Change in culture, household size and distance to the market center do not significantly influence a farmer's willingness to grow pearl millet at 5 percent significant level.

\begin{tabular}{|c|c|c|c|}
\hline Variable & Coefficient & Std. Error & $\mathbf{P}>\mathbf{z} \mid$ \\
\hline Age $^{* *}$ & 0.417 & 0.145 & 0.004 \\
\hline Educlev** $^{*}$ & 0.618 & 0.265 & 0.020 \\
\hline Hhsize & -0.252 & 0.247 & 0.308 \\
\hline Gender** & -3.659 & 1.704 & 0.032 \\
\hline Maristus & -3.934 & 1.691 & 0.220 \\
\hline Offaminc** & -0.0005 & 0.0002 & 0.045 \\
\hline Borrowd & -3.132 & 2.9047 & 0.281 \\
\hline landsize** & 1.372 & 0.506 & 0.007 \\
\hline Pastpalm & 5.6 & 5.943 & 0.346 \\
\hline Cultchag & 3.044 & 1.49 & 0.191 \\
\hline Dmkt & 0.091 & 0.282 & 0.746 \\
\hline Grsmargn & $-9.35 \mathrm{E}-06$ & 0.0001 & 0.930 \\
\hline Constant** & -23.963 & 11.526 & 0.038 \\
\hline Log likelihood & -16.304 & & \\
\hline Pseudo R2 & 0.692 & & \\
\hline LR chi2(16) & 73.24 & & \\
\hline Prob $>$ chi2 & 0 & & \\
\hline
\end{tabular}

Table 2: Binary Logistic Regression Model Results

(**) Represents the Significant Variables at 95 Percent Confidence Level

Table 3 reports the marginal effects derived after the binary logit regression. In the case of the continuous explanatory variables, the marginal effect relates to a one-unit change in the variable. For the binary explanatory variables, the marginal effect is the difference in probabilities between setting the explanatory variable to 1 and setting it to 0 , given that all other explanatory variables are set at their sample means. The marginal effects illustrate that a one-unit increase in household head age increases the probability of pearl millet adoption by 6.217 percent. An increase in the household's head level of education by one year increases the probability of pearl millet adoption by 9.206 percent. Households land size is the most influential factor in determining a farmer's willingness to adopt pearl millet growing. An increase in land size by one acre increases the probability of pearl millet adoption by 62.59 percent. 


\begin{tabular}{|l|l|l|l|l|}
\hline \multicolumn{1}{|c|}{ Variable } & \multicolumn{1}{c|}{$\mathbf{d y} / \mathbf{d x}$} & \multicolumn{1}{c|}{$\mathbf{P}>\mid \mathbf{z}$} & \multicolumn{1}{c|}{$\mathbf{Z}$} & \multicolumn{1}{c|}{ Std. Err } \\
\hline Age* $^{*}$ & 0.06217 & 0.03133 & 1.98 & 0.004 \\
\hline Educlev** $^{* * 1}$ & 0.09206 & 0.04779 & 1.93 & 0.02 \\
\hline Hhsize & -0.03756 & 0.03681 & -1.02 & 0.308 \\
\hline Gender* & -0.4145 & 0.22072 & -1.88 & 0.06 \\
\hline Maristus & -0.58641 & 0.37255 & -1.57 & 0.115 \\
\hline Offaminc & -0.00007 & 0.00005 & -1.49 & 0.137 \\
\hline Borrowd* & -0.65166 & 0.45298 & -1.44 & 0.15 \\
\hline Pastpalm* & 0.863694 & 0.1959 & 4.41 & 0.346 \\
\hline Cultchag* & 0.552262 & 0.26044 & 2.12 & 0.191 \\
\hline Land size** & 0.625905 & 0.35073 & 1.78 & 0.007 \\
\hline Dmkt & 0.013635 & 0.04321 & 0.32 & 0.752 \\
\hline Grsmargn & $-1.39 \mathrm{E}-06$ & 0.00002 & -0.09 & 0.93 \\
\hline y = Pr (wlnggrow) (predict) $=.817731$ & & & \\
\hline
\end{tabular}

Table 3: Marginal Effects

$\left({ }^{*}\right) \mathrm{dy} / \mathrm{dx}$ is for discrete change of dummy variable from 0 to 1

$\left.{ }^{* *}\right)$ Represents the significant variables at 95 percent confidence level

\section{Conclusions}

The study was conceptualized with the assumption that house hold size and distance to the market would have a positive influence on the farmer's willingness to grow pearl millet but the study results refute this assumption. The results indicate that household size and distance to the market are not statistically significant in influencing farmer's willingness to grow pearl millet. The fact that a farmer used to grow pearl millet in the past does not amount to the farmer being more willing to grow pearl millet than those who have no history of growing the crop. The study revealed that the more the respondent's level of education the more the willingness to grow pearl millet by the farmers. This contravenes the prior hypothesis that education level would negatively influence a farmer's willingness to grow pearl millet as the more educated were assumed to have more off-farm income opportunities. The study result alludes to the study done by Kebede et al., 1990; Adesina \& Seidi, 1995) that revealed that a farmer's education level bears a positive relationship with adoption of new crop enterprises. The higher the education level therefore the higher the willingness to adopt a new crop by farmers.

\section{References}

i. Adesina, A.A and Seidi, S., (1995). Farmers' perceptions and adoption of new agricultural technology: Analysis of modern mangrove rice varieties in Guinea-Bissau. Quarterly Journal of International Agriculture 34(4): 358-371

ii. Ayuk, E.T. (1997). Adoption of Agroforestry Technology: The Case of Live Hedges in the Central Plateau of Burkina Faso. Agricultural Systems 54: 189-206.

iii. Bagi, F.S., and C.J. Huang. 1983." Estimating Production Technical Efficiency for Individual Farms in Tennessee." Canadian Journal of Agricultural Economics 31:249-256

iv. Breustedt, G., Muller-Scheesel, J., \& Latacz-Lohmann, U. (2008). Forecasting the adoption of GM oilseed rape: Evidence from a discrete choice experiment in Germany. Journal of Agricultural Economics, 59(2), 237-256.

v. Caviglia-Harris, J.L. (2003). Sustainable Agricultural Practices in Rondônia, Brazil: Do Local Farmer Organizations Impact Adoption Rates? Economic Development and Cultural Change 52 (1): 23-50.

vi. Daberkow, S., \& McBride, W. (2003). Farm and operator characteristics affecting awareness and adoption of precision agriculture technologies in the US. Precision Agriculture, 4: 163- 177.

vii. FAO and ICRISAT, 1996. The World Sorghum and Millet Economies: Facts, Trends and Outlook. Basic Foodstuffs Service, FAO Commodities and Trade Division and the Socioeconomics and Policy Division, International Crops Research Institute for the Semi-Arid Tropics. ICRISAT, Andhra Pradesh; FAO, Rome

viii. Fernandez-Cornejo, J., \& McBride, W. (2002). Adoption of bioengineered crops (Agricultural Economics Report No. 810). Washington, DC: US Department of Agriculture Economic Research Service (USDA ERS).

ix. Fernandez-Cornejo, J., Daberkow, S., \& Huang, W-H. (1994). The adoption of IPM techniques by vegetable growers in Florida, Michigan and Texas. Journal of Agricultural and Applied Economics, 26(1): 158-172.

x. Fernandez-Cornejo, J., Mishra, A., Nehring, R., Hendricks, C., Southern, M., \& Gregory, A. (2007). Off-farm income, technology adoption, and farm economic performance (Agricultural Economics Report No. 36). Washington, DC: USDA ERS.

xi. Gujarat D.N (2003) Basic Econometrics 4th Edition. McGraw Hill Inc, New York.

xii. Gujarati, D.N. (1995). Basic Econometrics (3rd Ed.). McGraw-Hill International Editions.New York

xiii. Kebede, Y., Gunjal, K. and Coffin, G., 1990. Adoption of new technologies in Ethiopian agriculture: the case of Teguelet-Bulga District, Shoa Province. Agric. Econ., 4: 27-43.

xiv. Leisinger, K.M., Schmitt, K. and ISNAR (eds). (1995). Survival in the Sahel. An ecological and developmental challenge. Food Policy, Volume 21, Issue 3, The Hague

xv. Mangat, B. K., R. K. Maiti, I. S. Khairwal, (1999). Pearl Millet Breeding. Oxford and IBH Publ. Co. Pvt. Ltd., New Delhi 
xvi. Marra, M., Hubbell, B., \& Carlson, G. (2001). Information quality, technology depreciation, and Bt cotton adoption in the Southeast. Journal of Agricultural and Resource Economics, 26(1), 158-175.

xvii. Obilana, A. B. \&Manyasa, E. (2002). Millets.In: Belton PS, Taylor JRN (eds) Pseudocereals and less common cereals: grain properties and utilizationpotential. Springer-Verlag, Berlin Heidelberg New York, pp 177- 217.

xviii. Rasul G. and G. B. Thapa, (2003) Shifting Cultivation in the Mountains of South and South East Asia; Regional Patterns and Factors influencing the Change. Regional and Rural development Planning School of Environmental, Resources and Development, Asian Institute of Technology, Klong Luang, Thailand.

xix. Robert L. M, (2002). A New Grain Crop Option for Sandy Soils or Other Moisture-Limited Conditions, Jefferson Institute, Columbia,

xx. Rogers, E. (1995). Diffusion of innovations (4th ed.). New York: The Free Press. 